\title{
UMA PROPOSTA DE ATIVIDADES PRÁTICAS EM EDUCAÇÃO AMBIENTAL PARA O ENSINO FUNDAMENTAL
}

\author{
Maisa Cibele Pinto da Rosa', Marcelo Barcellos da Rosa² \\ ${ }^{1}$ Especialista em Educação Ambiental \\ ${ }^{2}$ Professores do Curso de Especialização em Educação Ambiental da UFSM
}

\begin{abstract}
RESUMO
Este artigo tem como objetivo principal contribuir com o aprimoramento e atuação em educação ambiental de professores do ensino fundamental. Através da pesquisa de atividades práticas que propiciem a interação entre a dimensão afetiva, cognitiva e motora, o estudo partiu da percepção de que muitos educadores apresentam dificuldades em ter acesso à uma educação ambiental consistente, bem como de encontrar referências pertinentes com características e prática da mesma. As atividades propostas basearam-se numa análise crítica e sustentada na experimentação, onde se objetivou sensibilizar as pessoas acerca das realidades socioambientais do seu mundo. Para isso, se buscou lançar desafios e identificar alternativas de soluções. A metodologia adotada foi a exploratória qualitativa. Esta abordagem tem um caráter holístico, prospectivo e acentua a importância da percepção das relações de interdependência dos sistemas de sustentação da vida, sob uma ótica do Ambiente Total e da manutenção e elevação da qualidade da Experiência Humana. Portanto, com esta pesquisa, uma proposta de atividades práticas foi pensada e desenvolvida de modo que possibilite, de maneira prazerosa, a disseminação de uma nova consciência e de atitudes com relação ao cuidado com o planeta que se habita.
\end{abstract}

Palavras-chaves: educação ambiental; proposta de prática pedagógica.

\section{ABSTRACT}

This work aims to contribute in the improvement and performance of the environmental education for teachers of elementary Schools. A literature review was performed and proposed to obtain a didactic tool, which was developed to be applied in Schools where the environmental education is constantly worked. The literature has pointed that the education is the principal key to change and propose new life's perspectives when we try to introduce new comportments using the environmental education as reference. Therefore, a didactic material involving environmental education was generated and can be applied and/or used with success in elementary Schools from south of Brazil.

Keywords: environmental education, formulation of didactic material.

\section{INTRODUÇÃO}

Segundo resoluções da Organização das Nações Unidas para a Educação, a Ciência e a Cultura (UNESCO) e o Programa das Nações Unidas para o Meio Ambiente (PNUMA) de 1997, a Educação Ambiental é conceituada como uma ferramenta que deve ser dirigida aos mais diversos grupos da 
coletividade, de acordo com suas necessidades e seus interesses, para que sensibilize a opinião desses grupos com relação aos problemas ambientais através de modificações nas atitudes, de novos conhecimentos e critérios.

A Educação Ambiental é uma forma de prática educacional sintonizada com a vida em sociedade. Ela só pode ser efetiva se todos os membros da sociedade participarem, de acordo com suas habilidades, das complexas e múltiplas tarefas de melhoria das relações das pessoas com seu meio ambiente. E isso só pode ser alcançado se as pessoas se conscientizarem do seu envolvimento e de suas responsabilidades e venham agir em prol de um propósito em comum.

Por ser um processo que deve durar por toda a vida, a Educação Ambiental pode ajudar a tornar mais relevante a educação geral, a começar pelo ensino fundamental com atividades práticas que proporcionem a aquisição de conhecimentos e habilidades capazes de induzir mudanças de atitudes nos educandos e educadores. Ela pode ser considerada como uma excelente base na qual se desenvolvam novas maneiras de viver sem destruir o meio ambiente, ou seja, em um novo estilo de vida.

Visando auxiliar professores da rede municipal de Campo Bom, RS e arredores, a iniciar um trabalho mais efetivo na escola, o presente trabalho propõe-se a sugerir uma série de atividades práticas organizadas na forma de uma cartilha didática, que servirá como uma ferramenta didática no ensino da Educação Ambiental, pois, nada como o caminho experimental para se talhar mudanças e disseminar entre as crianças e os jovens uma nova consciência e atitudes com relação ao cuidado com o planeta que habitamos de maneira mais prazerosa e significativa.

Ressaltando que a Educação Ambiental na escola não é uma solução "mágica" para os problemas ambientais, mas um processo contínuo de aprendizagem e de conhecimentos, bem como da prática de ser cidadão, capacitando o indivíduo para uma visão crítica da realidade e uma atuação consciente no espaço social. Não se trata de uma transferência de responsabilidades, mas a construção da responsabilidade no ambiente escolar pelas relações com a natureza, sociedade e cultura.

Completando esse pensamento, Dietz \& Tamaio (2000) advogam que se o educador quer promover uma cidadania ambiental crítica e responsável em seus educandos, deve saber que a pessoa aprende de forma integrada. Isto é, pensando, falando e fazendo; que só se aprende aquilo que faz sentido, que significa alguma coisa, e, portanto, precisa-se estar motivado, querer aprender. Ao educador compete essa mediação no processo de aprendizagem.

A educação ambiental, nas suas diversas possibilidades, abre um estimulante espaço para um repensar de práticas sociais e do papel dos professores como mediadores e como transmissores de um conhecimento necessário para que os alunos adquiram uma base adequada de compreensão essencial do meio ambiente global e local, da interdependência dos problemas e soluções e da importância da responsabilidade de cada um para construir uma sociedade planetária mais equitativa e ambientalmente sustentável.

Para o professor de nível fundamental e médio existe hoje um grande impasse: como realizar práticas de educação ambiental, que lhes são cobradas, sem que tenha sido preparado para isso e sem material em mãos?

Muitos educadores apresentam dificuldades ou, até mesmo, certa resistência quanto à inserção da Educação Ambiental em suas práticas educacionais, em suas atividades rotineiras. Isso se deve ao fato de termos poucas referências sobre práticas educativas ambientalistas. Com essa falta de referências sobre práticas, os professores, em geral, sentem-se "perdidos" em relação à Educação Ambiental. 
Portanto, esta monografia propõe-se a: contribuir para o aprimoramento e atuação em educação ambiental de professores do ensino fundamental, bem como propor sugestões de atividades práticas em Educação Ambiental para o ensino fundamental e discutir a importância das práticas de ensino aos professores do ensino fundamental para iniciarem um trabalho mais efetivo nas escolas;

\section{Evolução do Conceito de Educação Ambiental}

Stapp et al.(1969 apud Dias, 2010, p.98.), afirma que a Educação Ambiental era definida como um processo que deveria objetivar a formação de cidadãos, cujos conhecimentos acerca do ambiente biofísico e seus problemas associados pudessem alertá-los e habilitá-los a resolver seus problemas.

A Reunião Internacional sobre Educação ambiental da IUCN - Internacional Union for the Conservation of Nature (1970), definiu Educação ambiental como um processo de reconhecimento de valores e clarificação de conceitos, voltado para o desenvolvimento de habilidades e atitudes necessárias à compreensão e apreciação das inter-relações entre o homem, sua cultura e seu entorno biofísico.

Mellows (1972) apresentava a Educação Ambiental como um processo no qual deveria ocorrer um desenvolvimento progressivo de um senso de preocupação com o meio ambiente, baseado em um completo e sensível entendimento das relações do homem com o ambiente a sua volta.

Na conferência de Tbilisi (1977), a Educação Ambiental foi definida como uma dimensão dada ao conteúdo e à prática da educação, orientada para a resolução dos problemas concretos do meio ambiente, através de um enfoque interdisciplinar e de uma participação ativa e responsável de cada indivíduo e da coletividade.

Meadows (1989), também apresenta em uma publicação da Unep/Unesco, uma sequência de definições sobre Educação Ambiental, entre as quais destacam-se:

- É a aprendizagem de como gerenciar e melhorar as relações entre a sociedade humana e o ambiente, de modo integrado e sustentável;

- A preparação de pessoas para sua vida, como membros da biosfera;

- Significa aprender a empregar novas tecnologias, aumentar a produtividade, evitar desastres ambientais, minorar os danos existentes, conhecer e utilizar novas oportunidades e tomar decisões acertadas;

- O aprendizado para compreender, apreciar, saber lidar e manter os sistemas ambientais na sua totalidade;

- Significa aprender a ver o quadro global que cerca um dado problema - sua história, seus valores, percepções, fatores econômicos e tecnológicos, e os processos naturais ou artificiais que o causam e que sugerem ações para saná-lo.

Nos subsídios técnicos, elaborados pela Comissão Interministerial para a preparação da Rio92, a Educação Ambiental se caracterizava por incorporar a dimensão socioeconômica, política, cultural e histórica, não podendo basear-se em pautas rígidas e de aplicação universal, devendo considerar as condições e o estágio de cada país, região e comunidade, sob uma perspectiva holística. Assim sendo, a Educação Ambiental deve permitir a compreensão da natureza complexa do meio ambiente e interpretar a interdependência entre os diversos elementos que conformam o ambiente, 
com vistas a utilizar racionalmente os recursos do meio, na satisfação material e espiritual da sociedade, no presente e no futuro.

O Tratado de Educação Ambiental para Sociedades Sustentáveis e Responsabilidade Global (1992) reconhece a EA como um processo de aprendizagem permanente, baseado no respeito a todas as formas de vida.

O Conselho Nacional de Meio Ambiente - CONAMA (1996) - definiu a Educação Ambiental como um processo de formação e informação, orientado para o desenvolvimento da consciência crítica sobre as questões ambientais e de atividades que levem à participação das comunidades na preservação do equilíbrio ambiental.

Em 1997, por ocasião da Conferência Internacional sobre Meio Ambiente e Sociedade: Educação e Conscientização Pública para a Sustentabilidade (Unesco, Tessalônica, Grécia), definiu-se como um meio de trazer mudanças em comportamentos e estilos de vida, para disseminar conhecimentos e desenvolver habilidades na preparação do público, para suportar mudanças rumo à sustentabilidade oriundas de outros setores da sociedade.

Para Minini (2000), a Educação Ambiental é um processo que consiste em propiciar às pessoas uma compreensão crítica e global do ambiente, para elucidar valores e desenvolver atitudes que lhes permitiam adotar uma posição consciente e participativa, a respeito das questões relacionadas com a conservação e adequada utilização dos recursos naturais, para a melhoria da qualidade de vida e a eliminação da pobreza extrema e do consumismo desenfreado.

Segundo Dias (2010, p.98): “A evolução dos conceitos de Educação ambiental esteve diretamente relacionado à evolução do conceito de meio ambiente e ao modo como este era percebido.

\section{Educação Ambiental nas Escolas}

A educação ambiental é abrangente e permanente, ou seja, deve ser oferecida continuamente de modo crescente e continuado em todas as fases do ensino formal, envolvendo, ainda, a família e a coletividade. Além disso, considerar o meio ambiente em sua totalidade, envolvendo os aspectos natural, tecnológico, social, econômico, político, histórico, cultural, etc.

Portanto, é possível disseminar entre as crianças e os jovens uma nova consciência e atitudes com relação ao cuidado com o planeta que habitam, mas começando pela casa, escola, bairro e cidade. Assim, em muitos casos as propostas de educação ambiental para as escolas vêm sendo formuladas por órgãos governamentais, pelas redes de ensino público e privado. Muitos manuais dedicados ao tema tratam dos problemas ambientais de forma descontextualizada, omitindo-se os principais determinantes das suas causa e das suas consequências. Os interesses de pequenos grupos favorecidos ou de forças internacionais não são considerados nas propostas. Em muitos casos leva-se a crer que o patrimônio natural será melhor cuidado se for "repassado" aos países ditos desenvolvidos. Os interesses na Amazônia, em especial na biodiversidade brasileira não devem esquecidos. O Brasil é um país rico e ainda possui muitos elementos que só existem aqui.

$\mathrm{Na}$ sociedade, atribui-se à escola a função de desenvolver certos conhecimentos tidos como básicos, como a leitura e a escrita, a matemática e conceitos das ciências, da geografia e da história, entre outros. Considera-se que esses conhecimentos são úteis para que as pessoas possam ingressar no mundo do trabalho e participar das decisões sobre os rumos de seu país, exigir seus direitos e cumprir seus deveres. 
De acordo com Müller (1998), para conseguir que os alunos aprendam e que tais conhecimentos escolares sejam realmente úteis, o professor pode considerar alguns aspectos básicos, necessitando:

$\Leftrightarrow$ Tornar os conteúdos curriculares interessantes, aproximando-os de questões atuais e da vivência dos alunos.

$\leftrightarrow$ Integrar os diversos conteúdos, pois o amontoado de informações sem relação entre si, não é de fato, conhecimento;

$\Leftrightarrow$ Aproximar a escola do mundo do trabalho e da comunidade, para que a escola não se transforme numa prisão, fechada em si mesma e sem vida.

A questão ecológica pode ajudar o professor a enfrentar esses desafios. Em primeiro lugar porque, como os temas ambientais dizem respeito à relação entre o homem e a natureza, seu estudo facilita a integração entre outras disciplinas, como ciências, geografia, história, linguagem, entre outros. Além disso, a poluição, o desmatamento e as relações com a produção e conservação de energia são questões atuais que tem ocupado cada vez mais espaço nos meios de comunicação, permitindo que os professores encontrem exemplos e problemas do presente para ilustrar ou desenvolver os conteúdos escolares.

Logo, a interdisciplinaridade surge quando cada profissional faz uma análise do ambiente de acordo com seu saber específico, contribuindo para desvendar o real e apontando para outras leituras realizadas pelos seus semelhantes. O tema comum, extraído do cotidiano, integra e promove a interação de pessoas, áreas, disciplinas, produzindo um novo conhecimento mais amplo e coletivizado. As leituras, descrições, interpretações e análises diferentes do mesmo objeto de trabalho permitem a elaboração de um outro saber, que busca um entendimento e uma compreensão do ambiente por inteiro.

A educação ambiental, portanto não é responsabilidade apenas do professor de ciências. Ela é também responsabilidade da escola, que deve propiciar condições e mecanismos que favoreçam o diálogo e o trabalho conjunto dos professores e das disciplinas, para que, a partir disso seja realizado o trabalho interdisciplinar, no qual todos aprendem juntos.

Portanto a educação ambiental, como perspectiva educativa, pode estar presente em todas as disciplinas, quando analisa temas que permitem enfocar as relações entre a humanidade e o meio natural e as relações sociais sem deixar de lado as suas especificidades Reigota (2004).

A escola é um dos locais privilegiados para a realização da educação ambiental, desde que dê oportunidade à criatividade.

No planejamento da educação ambiental deve-se considerar que os conteúdos das diferentes áreas de conhecimento serão o ponto de partida para proceder-se a reelaboração com vistas à produção de novos conhecimentos, aplicados à realidade no sentido de transformá-la.

O conteúdo escolar é a apreensão sistematizada (conhecimento) de uma realidade. Se em uma aula o educador se deter apenas ao conteúdo pelo conteúdo, não o relacionando à realidade, estará descontextualizando esse conhecimento, afastando-o da realidade concreta, tirando seu significado e alienando-o. Dessa forma, minimiza-se o conhecimento como um instrumento para uma prática criativa.

Conforme Morin (2001), devemos ter a visão da globalidade, do intercâmbio, da interdisciplinaridade: - é a comunicação com a sociedade. Tudo no universo está ligado: pátria, nação, universalidade, identidade, ecologia, política, comunidade, etc. Tratar do meio ambiente de forma retalhada torna impossível apreender o que é "tecido junto", então, complexo, segundo o sentido geral da palavra. 


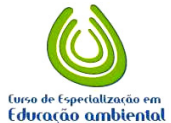

REMOA

\section{Monografias Ambientais}

(Revista Eletrônica do PPGEAmb-CCR/UFSM) ISSN:

A educação ambiental deve ser vivenciada a partir do trabalho prático buscando para a sala de aula, ou levando o aluno para local onde ele mesmo possa manusear e verificar animais, plantas, rios, banhados, usinas de lixo, enfim, para onde ele possa observar o mundo que o cerca.

Ao surgirem perguntas em sala de aula, será a demonstração de que o interesse surgiu e, então, haverá a continuidade. O planejamento e a imaginação fazem com que a criança entre num processo de eficiência integral da aprendizagem e, então tenha uma consciência em relação ao planeta Terra.

Sendo assim, a educação ambiental é um dos instrumentos mais importantes para promover a mudança necessária dos cidadãos, provocando abordagens discursivas, não somente sobre a Amazônia, mas sobre o que é de concreto em relação à coleta de lixo, ou ao não desperdício de energia. Isso sem falar da miséria das escolas sob o ponto de vista da ausência, quase que completa, de elementos da natureza, ausência esta que endurece e deforma a educação.

A Educação Ambiental - concebida como uma dimensão dada ao conteúdo e à prática orientada para a resolução dos problemas concretos do meio ambiente, através do enfoque transversal da participação ativa e responsável de cada indivíduo e da coletividade - se caracteriza por incorporar as dimensões éticas, sócio-econômicas, políticas, culturais e históricas.

Nas dimensões éticas, os indivíduos ou grupos sociais tomam consciência dos problemas e das características ambientais locais e globais, sensibilizando-se para essas questões. O compromisso com a diversidade de experiências deve ser somado em benefício do coletivo, para a compreensão fundamental do meio e dos problemas a ele relacionados. A contribuição deve ser para que haja uma postura paralela das pessoas para com os valores ambientais, para que se sintam preocupadas com o meio e motivadas para a participação. A qualidade de vida das pessoas está relacionada com o tomar conhecimento do verdadeiro objetivo do desenvolvimento nos tratos das questões ambientais, ou seja, a própria qualidade de vida do indivíduo.

Outro aspecto consensual sobre a educação ambiental é que não há limite de idade para os seus estudantes, tendo um caráter de educação permanente, dinâmica, variando apenas no que diz respeito ao seu conteúdo e à metodologia procurando adequá-los às faixas etárias a que se destinam.

Então, cabe a nós, educadores, desenvolver um trabalho que forme e informe a sociedade para uma conduta responsável, a ser adotada pelos indivíduos, pelas empresas e pelas comunidades, inspirada no sentido de sua responsabilidade, relativamente à proteção e melhoramento do meio ambiente em toda a dimensão humana.

Isso deixa claro que se precisa mudar a nossa postura em sala de aula e em casa, a fim de que venhamos a comprometer-nos. Cabe a cada um de nós fazer a parte que nos cabe, pois se não houver um processo educativo por trás das ações, não haverá mudança de atitude.

Meio Ambiente preservado é uma questão de educação e o professor tem a missão de fazer com que o aluno integre-se ao meio em que vive, pois a educação ambiental informal está interligada com o dia-a-dia do aluno.

O princípio transformador da educação ambiental é alcançado somente quando o conhecimento propiciado é ponderado pelos indivíduos e, uma vez aceito e assimilado, influencia a tomada de decisões, muitas vezes modificando uma atitude/ação e, consequentemente, transformando uma realidade posta.

Em função de tudo isso, a educação ambiental tem o importante papel de fomentar a percepção da realidade integração do ser humano com o meio ambiente. Uma relação harmoniosa, consciente do equilíbrio dinâmico na natureza, possibilitando, por meio de novos conhecimentos, 
valores e atitudes, a inserção do educando e do educador como cidadãos no processo de transformação do atual quadro ambiental do nosso planeta.

Por fim, a educação ambiental é mobilizadora, faz com que as pessoas tenham vontade de agir em prol de um propósito comum. Se todos perceberem o ambiente da mesma forma, tendem a compartilhar um objetivo. Esse objetivo é a mola propulsora que fará com que haja a união de esforços para a realização da atuação conjunta.

\section{METODOLOGIA}

O presente estudo foi desenvolvido a partir da observação de que muitos educadores têm dificuldades para ter acesso à formação ambiental, bem como de encontrar referências com características à prática da educação ambiental.

Para a realização desta pesquisa e busca de fundamentos teóricos, se propõe uma revisão bibliográfica de modo se obter e propor uma série de atividades práticas de caráter holístico, prospectivo e que destaque a importância da percepção das relações de interdependência dos sistemas de sustentação da vida. Esta se dá sob a ótica do Ambiente Total e da manutenção e elevação da qualidade da Experiência Humana (Boyden et al., 1981), à luz dos princípios e recomendações das Conferências Intergovernamentais sobre Educação Ambiental (Unesco/Unep/IEEP, Tbilisi, 1977; Moscou, 1987, Rio-92 e Thessaloniki, 1998) adotadas pelos Estados membros da Organização das Nações Unidas, bem como pela política Nacional de Educação Ambiental (lei 9.795/99).

A base para o desenvolvimento deste estudo foi o marco referencial de Dias (2010), no qual as atividades seguem a forma analítica e crítica, sustentada na experimentação, objetivando sensibilizar as pessoas acerca das realidades socioambientais do seu mundo, buscando examinar desafios e identificar alternativas de soluções.

As demais informações bibliográficas foram obtidas através de consultas nas bases da web: Google acadêmico, Scielo, CAPES, bem como fontes de informações da Biblioteca da Unisinos e Feevale.

Os levantamentos bibliográficos foram realizados entre maio de 2009 até a data de término da pesquisa.

Estabeleceu-se que cada umas das atividades focadas, como objeto de estudo, foram detalhadas com base nas fontes bibliográficas encontradas. Para tal sugeriu-se as categorias: título, recursos necessários e procedimento, mas para a utilização dessas atividades pode ser necessário algum tipo de adaptação, de acordo com o público e a situação, dependendo da finalidade do trabalho a ser realizado e da experiência de cada professor.

Para Kovaliczn (1999), o ensino de ciências, em sua fundamentação, requer uma relação constante entre a teoria e a prática, entre conhecimento científico e senso comum. Estas articulações são de extrema importância, uma vez que a disciplina de Ciências encontra-se subentendida como uma ciência experimental, de comprovação científica, articulada a pressupostos teóricos e assim, a idéia da realização de experimentos é difundida como uma grande estratégia didática para o ensino e aprendizagem. No entanto, não deve ser encarada como uma prática pela prática, de forma utilitária e sim uma prática transformadora, adaptada à realidade, com objetivos bem definidos, ou seja, a efetivação da práxis.

Ao realizar qualquer atividade relacionada com a Educação ambiental o professor deve ter em mente que é preciso usar o modelo do triângulo, que traz uma estratégia de como conscientizar os 
alunos de um modo geral, já que não existem atividades específicas de conscientização, pois isso é impossível, já que devemos primeiramente sensibilizá-los, depois formar o conhecimento a respeito do assunto e, por fim, a conscientização partirá de dentro de cada indivíduo, sem ultrapassar as sequências do triângulo, que segundo Müller (1998), inicia-se pela sensibilização.

A realização de atividades práticas representa uma excelente ferramenta para que o aluno concretize o conteúdo e possa estabelecer relação entre a teoria e a prática. Nesse sentido, a atividade experimental que pretende-se realizar deve ser desenvolvida sob a orientação do professor, a partir de questões investigativas que tenham consonância com aspectos da vida dos alunos e que se constituam em problemas reais e desafiadores. Com esse direcionamento o papel do professor é de orientador, mediador e assessor do processo, e isso inclui manter a motivação, lançar ou fazer surgir do grupo uma questão-problema, salientar aspectos que não tenham sido observados pelo grupo e que sejam importantes para o coletivo.

As atividades práticas de educação ambiental devem permitir, aos alunos, oportunidades de desenvolver uma sensibilização a respeito dos seus problemas ambientais e buscar formas alternativas de soluções, conduzindo pesquisas no ambiente urbano, relacionando fatores psicossociais e históricos com fatores políticos, éticos e estéticos.

Com isso, vamos identificar e definir problemas ambientais, coletar e organizar informações, gerar soluções alternativas, desenvolver e gerar um plano de ação.

O maior desafio é tornar o ensino de Ciências significativo e instigante, capaz de levar o aluno a construir seu conhecimento científico. Segundo Bondia $(2002$, p21) "pensar [...] é sobre tudo, dar sentido ao que somos e ao que nos acontece".

As atividades práticas propostas neste trabalho foram divididas em atividades de sensibilização ambiental e atividades ecológicas, pois ambas são importantes instrumentos da Educação Ambiental e buscam através de uma "vivência" sintetizar em poucos minutos uma reflexão acerca de uma experiência que nem sempre seria vivenciada no dia-a-dia.

As descrições das atividades podem ser encontradas em detalhes em APÊNDICE e seguem conforme as seguintes referências:

- Mapa dos sons, Caminhada perceptiva e Trilha das surpresas conforme Cornell, 1997;

- Bisbilhotando e Ordenar sem palavras, conforme Brotto, 2001;

- Custo de nossas escolhas, segundo Brusch, 2001;

- Como estamos cuidando das nossas Florestas, baseado em Urban, 1998;

- Aquecimento Global: de quem é a culpa? (IPAM. 2008);

- Percebendo a cidade como um tipo especial de ecossistema, Existe fauna urbana? e Caçada ecológica, baseado em Dias, 2010;

- Caçada ecológica, Ache seu parceiro, Impacto ambiental, Preciosidades, Procura-se e Melhorando o ambiente escolar, proposto por Sperb, 1999

\section{RESULTADOS E DISCUSSÃO}

Considera-se que o papel da escola constitui em preparar o aluno para as diversas situações da vida. Para tanto, se faz necessário a utilização de diferentes métodos e estratégias para o desempenho do processo de ensino-aprendizagem, interligando os conteúdos abordados em sala de aula às vivências dos alunos, pois é fundamental que os alunos percebam o meio em que estão inseridos a fim de despertá-los para a importância de preservar a presente e as gerações futuras. Vale ressaltar que a percepção é o primeiro passo para que as pessoas se conscientizem dos problemas 
socioambientais, fazendo com que passem a inserir pequenas mudanças positivas em seu cotidiano, contribuindo para o bem estar global.

Mas as mudanças não devem se limitar a aspectos comportamentais, do indivíduo, mas sim em sua inserção na sociedade, de modo mais amplo, político, crítico e social, pois não devemos ver nossos alunos como agentes do futuro, mas como agentes hoje, capazes de tomar e influenciar decisões que podem ser ou não para o bem comum da sociedade e da natureza.

De acordo com Krasilchik (1996), quanto mais as experiências educativas assemelham-se às futuras situações em que os alunos deverão aplicar seus conhecimentos, mais fácil se tornará a concretização do aprendizado. Diante disso, acredita-se que o professor tem importante função e responsabilidade de planejar atividades práticas para facilitar a compreensão dos conteúdos teóricos aos alunos, estimulando-os a questionar, responder, observar, explorar, analisar, comparar e compreender a situação problema, levando ao desenvolvimento de novos conhecimentos, uma vez que o acesso ao conhecimento novo ocorre a partir do pré-existente.

Reigota (1994), alerta que a prática da Educação Ambiental depende da concepção das pessoas sobre o meio ambiente, para então podermos iniciar um programa de construção de conhecimento que fomente a necessária modificação de valores e condutas pró-ambientais de forma crítica e responsável.

Portanto, a realização de atividades práticas representa uma excelente ferramenta para que o aluno concretize o conteúdo e possa estabelecer relação entre a teoria e a prática. Nesse sentido, Dias (2010, p. 217), afirma que "a prática aplicada deve ser desenvolvida sob orientação do professor, pois este é o principal mediador nas questões investigativas e que se constituam em problemas reais e desafiadores".

As afirmações acima apontam o mesmo que Edgar Dale (1969 apud Dias, 2010, p.218), enfatiza que "o ensino puramente teórico (simbólico-abstrato) deve ser evitado. O imediatamente vivencial permite uma aprendizagem mais efetiva".

Cabe concordar com as afirmações citadas, pois nestes quatorze anos de magistério, posso afirmar que durante as realizações de avaliações de final trimestre, o que mais os alunos salientam é o gosto pelas atividades práticas realizadas, pois são as que mais marcam o aprendizado.

Outro aspecto importante para ser salientado é que o educador não se preocupe em ser o "dono da verdade", durante as atividades práticas, mas sim alguém que ajude os educandos a buscarem soluções de forma criativa, motivadora e eficaz.

Segundo Paulo Freire (1997), os educadores devem ser críticos e compromissados com a promoção das pessoas com as quais vai trabalhar. $O$ respeito às individualidades, à cultura e necessidades socioeconômicas devem ser levados em conta. Deve-se enfatizar o presente, o passado e o futuro para entender a realidade e construir um mundo melhor.

O aluno precisa se sentir atuante e transformador de sua realidade e não meramente um observador, pois é necessário enxergar sentido no que está realizando, e dessa forma refletir sobre sua realidade na qual vive, levando a compreensão de que é um ser ativo no contexto social e histórico contribuindo para a construção de um cidadão consciente de suas ações.

Para a superação dessa realidade, seria necessário investir na formação inicial e continuada de professores, já que esta, é um processo contínuo e que não se inicia e muito menos se finda em um curso de graduação, tal como licenciaturas.

A realização de atividades de sensibilização como estratégia pedagógica oportuniza a vivência de situações e não apenas a transmissão de informações, favorecendo a aprendizagem significativa e discussão das relações das pessoas entre si e/ou destas com a realidade, pois a intensidade do 
aprendizado não se dá só através de experiências externas, mas também pela intensidade da emoção vivida durante uma experiência.

Ressalta-se também que as atividades de sensibilização favorecem a participação e ação dos envolvidos, porém devem ser utilizadas, respeitando-se uma série de elementos: afinidade de interesses, organização, objetivos, tipo e tamanho do grupo de alunos, espaço, tempo disponíveis e recursos entre outros. Não esquecendo que cada atividade deve se adaptada a cada situação: local, idade dos participantes, linguagem, entre outros.

$\mathrm{Na}$ atividade proposta: "Mapa dos sons", pode-se perceber que a escuta de sons, possibilita a percepção de forma integral dos sons e mensagens que permeiam a vida cotidiana, requerendo o reconhecimento de que estamos rodeados por diferentes sons naturais e produzidos, inclusive nas grandes cidades, onde muitas vezes são percebidos apenas como poluição sonora e não como mensagens do próprio meio ambiente. Outro aspecto que esta atividade favorece é que propicia uma atividade de respeito e aprendizagem quanto ao saber ouvir outra pessoa, fator este primordial para uma boa convivência humana. E na atividade "Caminhada perceptiva" percebe-se que são aguçados os sentidos do tato, por meio do contato direto e exploração dos elementos da natureza. Elementos esses importantes e merecedores de respeito, pois cada um deles possui sua função dentro do sistema e está interligado com todos os demais elementos, formando uma rede de relações que fundamentalmente é responsável pela manutenção da vida na Terra.

Já a atividade "Bisbilhotando" possibilita o exercício de mudança de perspectiva, a partir de uma visão mais restrita ou mais geral, dependendo da forma e da percepção de cada olhar. Pois conforme Müller (1998), um dos princípios básicos da educação ambiental é de que ela deve ser globalizadora, devendo considerar o ambiente em seus múltiplos aspectos e atuar com visão ampla de alcance local, regional e global. Embora sua atuação deva ser voltada para a resolução de problemas concretos do meio ambiente, ou seja, aqueles específicos, que afetam diretamente os indivíduos e a coletividade, a visão deve sempre remeter ao geral e ao global para que os objetivos e finalidades não se percam.

Segundo Brotto (2001), a escolha pelo caminho dos jogos cooperativos como um exercício de convivência favorece o desenvolvimento pessoal e a convivência social, visto que os participantes jogam uns com os outros e não uns contra os outros, superando o paradigma do individualismo para a consciência da cooperação. Objetivo este encontrado na atividade "Ordenar sem palavras", pois propicia a expressão não verbal entre os participantes do grupo, além de favorecer a confiança e atitude cooperativa num desafio coletivo.

Por fim, os objetivos das atividades práticas de sensibilização ambiental facilitam e possibilitam o processo educativo-participativo, uma vez que o conhecimento e a compreensão da realidade são mais facilmente alcançados pela vivência do que pela informação, favorecendo a sensibilização dos alunos com relação às questões socioambientais e de sua localidade, possibilitando a discussão de valores relacionados a uma ética ambiental de respeito à vida.

No entanto, as atividades ecológicas são uma forma estimulante para os alunos, pois por meio de uma prática, entram em contato com o ambiente natural, possibilitando um maior entendimento da dinâmica de um determinado ecossistema. E o importante é que estas atividades tenham como finalidade principal o despertar da comoção dos alunos para com a natureza, pois a assimilação dos conhecimentos teóricos acontece naturalmente durante a vivência.

As atividades ecológicas devem ser aplicadas de preferência em um ambiente natural, porém existem algumas atividades que podem ser realizadas em ambientes fechados, mas isso depende da criatividade e da motivação de cada educador. 


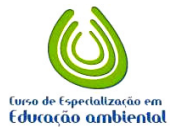

REMOA

\section{Monografias Ambientais}

(Revista Eletrônica do PPGEAmb-CCR/UFSM) ISSN:

O professor deve procurar realizar suas práticas em visitas aos parques, zoológicos, jardins botânicos, bosques, entre outros, mostrando aos alunos o dinamismo presente na natureza: nos animais, pelo som, audição, visão; nos vegetais, através do crescimento das folhas, caules, raízes e frutos, mostrando sempre a relação entre animais e plantas (alimentação, moradia) ou plantas e animais (polinização, dispersão pelos insetos, roedores, etc.). Despertar o sentimento de que este dinamismo é harmônico entre cada elemento da natureza e nas suas inter-relações biológicas, criando no aluno uma dimensão afetiva para com a natureza circundante. Tudo isso para que o educando perceba que o homem mantém uma relação afetiva, ainda que inconsciente, com a natureza, necessitando mantê-la sempre junto de si, pois é necessário perceber que tudo o que o cercam faz parte do ambiente, a terra em que pisa a água que bebe, o ar que respira e todos os seres com os quais convive e se relaciona, inclusive ele próprio.

Um exemplo de atividade ecológica é a "Trilha de surpresas", que visa ampliar a percepção visual dos alunos em relação aos elementos existentes no local, através da vivência de uma atividade realizada em área verde. Fato este que favorece a aprendizagem, pois mais informações chegam até as pessoas através dos olhos do que por meio de sistemas sensoriais da audição, olfato, paladar e tato.

De acordo com Cornell (1997) é preciso lembrar que as atitudes e ações cotidianas de cada pessoa e da coletividade têm relação direta com os seus valores e sua visão de mundo. Enquanto os seres humanos não conseguem enxergar com clareza e se considerarem seres à parte da natureza, não serão capazes de interagir de maneira equilibrada com os demais elementos que formam a teia da vida.

Outras atividades citadas são "O custo de nossas escolhas" e "Percebendo a cidade como um tipo especial de ecossistema" que tem como objetivo mostrar como os seres humanos contribuem diretamente para aumentar a pressão de demanda sobre os recursos naturais, a partir dos hábitos de consumo. Outro aspecto que se pode analisar é a qualidade do ambiente, observando seus pontos positivos e negativos, notando falhas e identificando alternativas de soluções. Já a atividade "Como estamos cuidando das nossas florestas?" tem como objetivo analisar a manutenção das florestas, tendo em vista a sua forma de utilização pela sociedade atual, proporcionando o exercício da cidadania, fazendo com que os alunos valorizem o que os cercam e compreendam melhor a dinâmica do ambiente, reconhecendo ameaças e descobrindo formas de conservá-lo.

$\mathrm{E}$ as atividades "Aquecimento global: "De quem é a culpa?" , "Impacto ambiental" e "Preciosidades" visam desenvolver no aluno a capacidade de pesquisar e procurar soluções para situações problema, criando a noção de agente transformador do ambiente e mostrando a possibilidade de discussão e intervenção nas atividades humanas.

Nas atividades "Existe fauna urbana?", "Caçada ecológica" e "Ache seu parceiro", o objetivo é estabelecer relações mais harmônicas entre as pessoas e os demais seres que compõem o meio ambiente, reconhecendo-os e respeitando-os. Por fim as atividades: "Procura-se" e "Melhorando o ambiente escolar" permitem valorizar e formular valores que lavam a mudanças de atitudes no dia-adia para contribuir com a preservação do meio ambiente.

O presente estudo mostrou, através da fundamentação teórica e das propostas de atividades práticas, a possibilidade de viabilizar a utilização constante de práticas no ensino da Educação Ambiental. Assim sendo, pode-se perceber que os objetivos aos quais este trabalho se propôs foram alcançados.

Mas vale ressaltar que as questões aqui propostas não são fechadas, pois através de adaptações com relação aos temas tratados e/ou conteúdos abordados poderia se estender a 
aplicabilidade das mesmas, fazendo com que estas possam ser trabalhadas em outras séries da Educação Básica.

Espera-se que as propostas de trabalho aqui apresentadas possam servir de base e de inspiração para outros educadores que estejam interessados em aprimorar seu método de ensino, bem como melhorar o desempenho e aproveitamento de seus alunos.

\section{CONCLUSÃO}

A utilização de atividades práticas no ensino da educação ambiental como estratégia de ensino é uma excelente ferramenta. Ela proporciona aos educandos a sensibilização e a vivência de maneira mais prazerosa, gerando aumento da participação e interesse dos mesmos a respeito dos assuntos abordados, pois promovem motivação e facilitam a construção do conhecimento no processo de ensino-aprendizagem.

A motivação dos alunos ao participarem de uma atividade reafirma a fundamental importância da aplicação de atividades práticas no processo de aprendizagem, principalmente quando estas se realizam em ambientes naturais, proporcionando o contato direto com o meio.

O trabalho com atividades práticas proporciona ao professor uma mudança de postura e uma chance de repensar a prática pedagógica, pois possibilita uma interação maior entre educador e educando. Aliando a teoria e a prática é possível disseminar entre as crianças e os jovens uma nova consciência e atitudes com relação ao cuidado com o planeta que habitamos.

Com o desenvolvimento desta pesquisa foi organizado um material didático com sugestões de atividades práticas em educação ambiental (ver Apêndice), que servirá de subsídio para os educadores ministrarem suas aulas de maneira mais efetiva e objetiva, de modo atender de forma consistente e plena os objetivos propostos nesta monografia. Portanto, acredita-se que a cartilha didática obtida desta pesquisa propiciará aos alunos oportunidades de ampliação da sua percepção em relação ao meio que os cercam. Além disso, é importante salientar que cada atividade está aberta à criatividade de cada educador, podendo adaptá-la de acordo com sua realidade, público alvo, situação, finalidade e experiência de cada professor.

Assim, acredita-se que a educação seja a "chave" para um novo modelo de vida.

\section{REFERÊNCIAS BIBLIOGRÁFICAS}

BRASIL. Constituição (1988). Constituição da República Federativa do Brasil. São Paulo: ATLAS, 1990. BRASIL, Ministério da Educação e do Desporto. Lei de Diretrizes e Bases da Educação Nacional, 1999. , Secretaria de educação fundamental. Parâmetros curriculares nacionais. Terceiro e quarto ciclos do ensino fundamental - Brasília: MEC/SEF, 1998.

BONDIA, J. L. Notas sobre a experiência e o saber da experiência. Revista Brasileira, n19, p. 20-28. 2002. Disponível em: < http://www.anped.org.br/rbe/rbedigital>. Acesso em: 20 jun. 2010.

BOYDEN, S. et al. The Ecology of a City and is People. Canberra, Australian National University, 1981, 437p.

BROTTO, F. O. Jogos cooperativos- o jogo e o esporte como um exercício de convivência. Santos/SP: Projeto Cooperação, 2001.

BURCH. A. M. Simplicidade - ideias, exemplos e exercícios para conquistar uma prosperidade inimaginável. São Paulo, Cultrix, 2001.

CORNELL, J. A alegria de aprender. São Paulo: Senac, 1997. 
CURRIE, K. L. Meio ambiente, interdisplinaridade na prática. Campinas, Papirus, 1998.

DECLARAÇÃO DE TBILISI. Global Development Research Center. Disponível em: http://www.gdrc.org/uem/ee/tbilisi.html. Acesso em: 27 jun. 2010.

DIAS, G. F. Atividades Interdisciplinares de Educação Ambiental. 2.ed. São Paulo: Gaia, 2006.

DIAS, G. F. Educação Ambiental: princípios e práticas. 9. ed. São Paulo: Gaia, 2010.

DIETZ, L. A. ; TAMAIO I. Aprenda fazendo: apoio aos processos de educação ambiental. WWF Brasil, 2000.

FREIRE, P. Pedagogia da Autonomia: saberes necessários à prática pedagógica. 12 ed. São Paulo: Paz e Terra, 1997.

GUIMARÃES, M. A dimensão ambiental na educação. Campinas, SP: Papirus, 1995.

INSTITUTO BRASILEIRO DO MEIO AMBIENTE E DOS RECURSOS NATURAIS RENOVÁVEIS. Educação para um futuro sustentável: uma visão transdisciplinar para ações compartilhadas / UNESCO. Brasília: Ed. IBAMA, 1999.

INSTITUTO DE PESQUISAS AMBIENTAL DA AMAZÔNIA. Perguntas e respostas sobre mudanças climáticas. Belém. PA. 2008.

KRASILCHIK, M. Educação Ambiental na escola brasileira: passado, presente e futuro. Revista Ciência e Cultura, ano 38, n.12, p 1958-1961, dezembro de 1996.

KOVALICZN, R. A. O professor de Ciências e de Biologia frente as parasitoses comuns em escolares. Mestrado em Educação. UEPG, 1999.

MARK. A. B. Simplicidade: idéias, exemplos e exercícios para conquistar uma prosperidade inimaginável. São Paulo: Cultrix, 2001.

MEADOWS, D.H. Harvesting one Hundreafold. Unep/Unesco,1989.

MEDINA. N. M. Breve histórico da educação ambiental. Disponível em:< http://www.sescse.com.br>. Acesso em: 19/06/2010

MELLOWS, C. Environmental Education and the Search for Objectives. Environmental Education: the Present and the Future Trends. Portsmouth, no 6. 1972.

MININI, N. A formação dos professores em Educação ambiental. In: Textos sobre capacitação em Educação Ambiental. Oficina Panorama da Educação Ambiental, MEC-SEF-DPEF- Coordenação de Educação Ambiental, Brasília, 2000.

MINISTÉRIO DO INTERIOR (MINTER), IBAMA. Programa Nossa Natureza - Leis e Decretos. Brasília, 1989.

MORIN, E. Os sete saberes necessários à educação do futuro. São Paulo: Cortez; Brasília, 2001.

MÜLLER, J. Educação Ambiental Diretrizes para a Prática pedagógica. Porto Alegre: FAMURS, 1998

REIGOTA, M. O que é Educação ambiental. 6.ed. São Paulo: Brasiliense, 2004 RIO GRANDE DO SUL. Secretaria Estadual do Meio Ambiente. CódigoEstadual de Meio Ambiente. Lei Estadual $\mathbf{N}^{\circ}$ 11.520/2000. Porto Alegre: 2000.

SPERB. B. Atividades práticas em Educação Ambiental.1999. 84f. Trabalho de conclusão para obtenção de habilitação em Biologia. Universidade do Vale do Rio dos Sinos - UNISINOS. São Leopoldo,1999.

STAP, W.B. et al. The Concept of Environmental Education. The Journal of Environmental Education, v.1 nำ1, 1989.

TRATADO DE EDUCAÇÃO AMBIENTAL PARA SOCIEDADES SUSTENTÁVEIS E RESPONSABILIDADE GLOBAL ,1992. Disponível em:< http://www.pr.gov.br/meioambiente/educ tratado.shtml $>$.Acesso em 20 jul. 2010. 


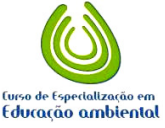

REMOA

\section{Monografias Ambientais}

(Revista Eletrônica do PPGEAmb-CCR/UFSM) ISSN:

UNESCO/PNUMA. Seminário Internacional de Educação Ambiental. Belgrado, Yuguslávia. Informe Final. Paris, 1977.

URBAN. T. Saudade do matão: relembrando a história da conservação da natureza no Brasil. Curitiba: UFPR, 1998. 